\title{
Improved Method for Determination of
} Raspberry Ketone in Fragrance Mist by HPLC-Fluorescence Analysis after Pre-Column Derivatization with

\section{4-( $N, N$-Dimethylaminosulfonyl)-7- ( $N$-chloroformylmethyl- $N$-methylamino) -2,1,3-benzoxadiazole}

\section{Yasuhiko Higashi}

Department of Analytical Chemistry, Faculty of Pharmaceutical Sciences, Hokuriku University, Ho-3, Kanagawa-machi, Kanazawa, Japan

Email: y-higashi@hokuriku-u.ac.jp

How to cite this paper: Higashi, Y. (2018) Improved Method for Determination of Raspberry Ketone in Fragrance Mist by HPLC-Fluorescence Analysis after PreColumn Derivatization with 4-( N,N-Dimethylaminosulfonyl)-7-( $N$-chloroformylmethyl- $N$-methyla-mino)-2,1,3-benzoxadiazole. Journal of Analytical Sciences, Methods and Instrumentation, 8, 17-24. https://doi.org/10.4236/jasmi.2018.82002

Received: March 29, 2018

Accepted: June 9, 2018

Published: June 12, 2018

Copyright $\odot 2018$ by author and Scientific Research Publishing Inc. This work is licensed under the Creative Commons Attribution International License (CC BY 4.0).

http://creativecommons.org/licenses/by/4.0/

\begin{abstract}
Raspberry ketone $\{\mathrm{RK}, 4$-(4-hydroxyphenyl)butan-2-one $\}$ is structurally resembles 4-(4-hydroxyphenyl)-2-butanol, which causes leukoderma on consumers' skin. Therefore, it is important to measure in cosmetics for quality assessment. Very recently, an HPLC-fluorescence method for determination of RK in a fragrance mist by pre-column derivatization with 4-hydrazino-7nitro-2,1,3-benzoxadiazole hydrazine was established. However, the derivatization conditions $\left(80^{\circ} \mathrm{C}, 20 \mathrm{~min}\right)$ were severe. In this study, an improved pre-column derivatization with 4 -( $N, N$-dimethylaminosulfonyl)-7-( $N$-chloroformylmethyl- $N$-methylamino)-2,1,3-benzoxadiazole (DBD-COCl) is presented by HPLC-fluorescence method for determination of RK. The DBD-CO-RK derivative was eluted from a reversed-phase ODS column, and detected with excitation at $440 \mathrm{~nm}$ and emission at $543 \mathrm{~nm}$. Derivatization was performed at room temperature for $3 \mathrm{~min}$. The retention time of $\mathrm{DBD}-\mathrm{CO}-\mathrm{RK}$ derivative was $16.8 \mathrm{~min}$. The standard curve was linear in the range of 0.05 to $2.5 \mu \mathrm{g} / \mathrm{mL}$, with a correlation coefficient $\left(r^{2}\right)$ value of 0.9988 . The lower limit of detection was $0.01 \mu \mathrm{g} / \mathrm{mL}$ (absolute amount of $0.3 \mathrm{pmol}$ ). The coefficients of variation were less than $10.0 \%$. The content of RK in fragrance mist $(1.00 \mathrm{~mL})$ was 1.20 $\pm 0.08 \mathrm{mg}$ (range, 1.10 to $1.31 \mathrm{mg}, n=5$ ). Recovery tests were satisfactory
\end{abstract}


$(91.8 \pm 5.4 \%$; range, 84.2 to $98.2 \%, n=5)$.

\section{Keywords}

Raspberry Ketone, High-Performance Liquid Chromatography,

4-( $N, N$-Dimethylaminosulfonyl)-7-( $N$-chloroformylmethyl- $N$-methylamino)-

2,1,3-benzoxadiazole, Derivatization, Fluorescence

\section{Introduction}

Raspberry ketone $\{\mathrm{RK}, 4$-(4-hydroxyphenyl)butan-2-one $\}$, which is present in red raspberry, was reported to have an anti-obesity effect [1] [2] [3], to possess a depigmenting activity in C57 black mice [4], to inhibit melanogenesis in cultivated murine B16 melanoma cells [5] and to suppress proliferation of normal melanocytes [6]. These findings indicated that RK would be useful for skin whitening, and RK-added cosmetics are already commercially available. In addition, cosmetics containing rhododendrol \{4-(4-hydroxyphenyl)-2-butanol\}, which structurally resembles RK, were withdrawn from the market in July 2013, because of observation of leukoderma on consumers' hands and face [7]. Thus, it seems important to measure the RK level in cosmetics, since RK may induce advertised effects like those of 4-(4-hydroxyphenyl)-2-butanol.

High-performance liquid chromatographic (HPLC) methods with ultraviolet-visible absorption detection and gas chromatographic (GC) method using a flame ionization detector have been developed to determine raspberry ketone [8] [9] [10]. Although a coupled loop-type HPLC-GC method was established for analysis of RK in raspberry sauce, this technique may be unsuitable for broad application [11]. In addition, GC and HPLC methods coupled with mass spectrometry have been utilized for RK determination, but the equipment is expensive and complex [12] [13]. Very recently, HPLC-fluorescence determination of RK was developed using pre-column derivatization with 4-hydrazino-7-nitro-2,1,3-benzoxadiazole (NBD-H) [14]. While the assay possessed low cost and exhibited a high sensitivity (absolute amount of $1.8 \mathrm{pmol}$ ), optimum derivative conditions were relatively severe $\left(80^{\circ} \mathrm{C}, 20 \mathrm{~min}\right)$.

RK possesses a phenolic hydroxyl group as well as a carbonyl group in the chemical structure. NBD-H reacts toward a carbonyl group of RK. Several papers about HPLC-fluorescence method after mild and rapid derivatization (at room temperature, for $3 \mathrm{~min}$ ) using acyl chloride compounds toward a phenolic hydroxyl group were reported [15] [16] [17]. Therefore, in the present study, an HPLC-fluorescence method for determination of RK in a fragrance mist after pre-column derivatization with an acyl chloride compound, 4-( $N, N$-dimethylaminosulfonyl)-7-( $N$-chloroformylmethyl- $N$-methylamino)-2,1 ,3-benzoxadiazole (DBD-COCl), was established. The derivatization scheme is shown in Figure 1. 
<smiles>[R4]C(=O)Oc1ccc(Oc2ccc(N(C)CC(=O)Oc3ccc(N(C)C)c4nonc34)c3nonc23)cc1</smiles>

Figure 1. Derivatization reaction scheme for RK.

\section{Experimental}

\subsection{Materials}

RK and DBD-COCl were purchased from Tokyo Chemical Industry Co., Ltd. (Tokyo, Japan). Fragrance mist was obtained via the internet. Acetonitrile and distilled water for HPLC was purchased from Kanto Chemical Co., Inc. (Tokyo, Japan). Trifluoroacetic acid was obtained from Wako Pure Chemical Industries (Osaka, Japan).

\subsection{HPLC Instrumentation and Chromatographic Conditions}

The HPLC system consisted of a model L-6200 pump (Hitachi, Tokyo, Japan), a Rheodyne injection valve (Cotati, CA, U.S.A.) with a $20-\mu \mathrm{L}$ loop, and a model RF-10A $A_{\mathrm{XL}}$ fluorescence spectrophotometer (Shimadzu, Kyoto, Japan) with excitation at $440 \mathrm{~nm}$ and emission at $543 \mathrm{~nm}$. A $150 \mathrm{~mm} \times 3.0 \mathrm{~mm}$ i.d. HPLC column (ODS-4, GL Science, Tokyo) containing $5 \mu \mathrm{m}$ particles of $\mathrm{C}_{18}$ packing material was used. Peak quantification was performed using a model C-R3A Integrator (Shimadzu). The mobile phase was prepared by the addition of acetonitrile $(450 \mathrm{~mL})$ to $550 \mathrm{~mL}$ of Milli-Q water containing trifluoroacetic acid $(0.1 \% \mathrm{v} / \mathrm{v})$. Samples were eluted from the column at room temperature at a flow rate of $0.5 \mathrm{~mL} / \mathrm{min}$.

\subsection{Preparation of Standard Solutions, Lower Limits of Detection and Quantification}

After dissolving RK $(5.0 \mathrm{mg})$ in methanol $(1.0 \mathrm{~mL})$, standard stock solution (50 $\mu \mathrm{g} / \mathrm{mL}$ ) was prepared by dilution with distilled water and stored at $4^{\circ} \mathrm{C}$. Working standard solutions $(0,0.05,0.1,0.25,0.5,1, .1 .5$ and $2.5 \mu \mathrm{g} / \mathrm{mL})$ were prepared by dilution with distilled water. Determination of lower limit of detection (LOD) and lower limit of quantification (LOQ) was based on the standard deviation (SD) of the response and on the slope of the calibration curve $(0.05,0.1,0.25$ $\mu \mathrm{g} / \mathrm{mL}$ ), according to the following equations: $\mathrm{LOD}=3.3 \times \mathrm{SD} /$ slope, $\mathrm{LOQ}=10$ 
$\times \mathrm{SD} /$ slope

\subsection{Derivatization}

Borate buffer $(0.1 \mathrm{M})$ was adjusted to $\mathrm{pH} 9.0$ by the addition of $\mathrm{NaOH}$. Borate buffer $(50 \mu \mathrm{L})$ was added to diluted standard samples $(50 \mu \mathrm{L})$. DBD-COCl solution in acetonitrile $(2 \mathrm{mg} / \mathrm{mL}, 100 \mu \mathrm{L})$ was added and vortexed. The mixture was allowed to react for $3 \mathrm{~min}$ at room temperature. Saturated L-aspartate solution $(50 \mu \mathrm{L})$ was added to stop the reaction, and aliquots $(20 \mu \mathrm{L})$ were injected into the HPLC system.

\subsection{Application to Fragrance Mist Sample and Evaluation of Recovery}

Fragrance mist was diluted 1600 -fold with distilled water, and then analyzed as described above. Fragrance mist $(1.0 \mathrm{~mL})$ was spiked with $1.0 \mathrm{mg}$ of RK, and spiked sample was diluted 1600 -fold with distilled water. The resulting sample was analyzed to determine recovery of the added standard in order to assess the accuracy of the method.

$$
\operatorname{Recovery}(\%)=\frac{(\text { Total amount after spiking })-(\text { Spiked amount })}{(\text { Original amount })} \times 100
$$

\section{Results and Discussion}

\subsection{Time Course of Derivatization of RK with DBD-COCl}

For the time course study, the reaction time was set at 1.5, 3, 5, 10, and $15 \mathrm{~min}$. RK $(50 \mu \mathrm{L}, 1 \mu \mathrm{g} / \mathrm{mL})$, borate buffer (50 $\mu \mathrm{L}, \mathrm{pH} 9.0)$ and DBD-COCl $(50 \mu \mathrm{L}, 2$ $\mathrm{mg} / \mathrm{mL}$ ) were mixed as described in 2.4. Derivatization. The maximum peak area was reached at $3 \mathrm{~min}$ (Figure 2(a)). Next, $\mathrm{pH}$ dependency ( $\mathrm{pH} 7.5$ to 10.0) was examined at the derivatization time of $3 \mathrm{~min}$ (Figure 2(b)). Peak area of DBD-CO-RK

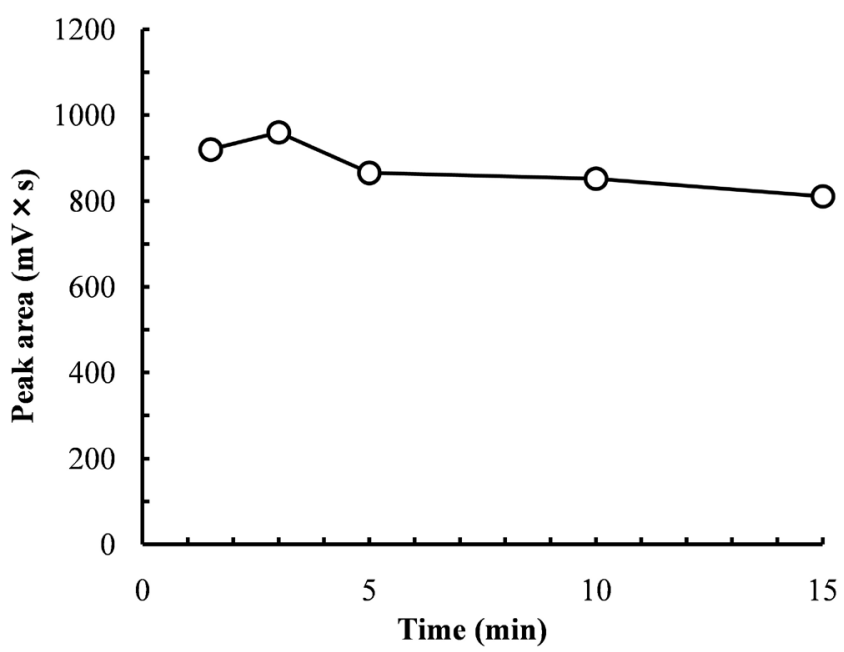

(a)

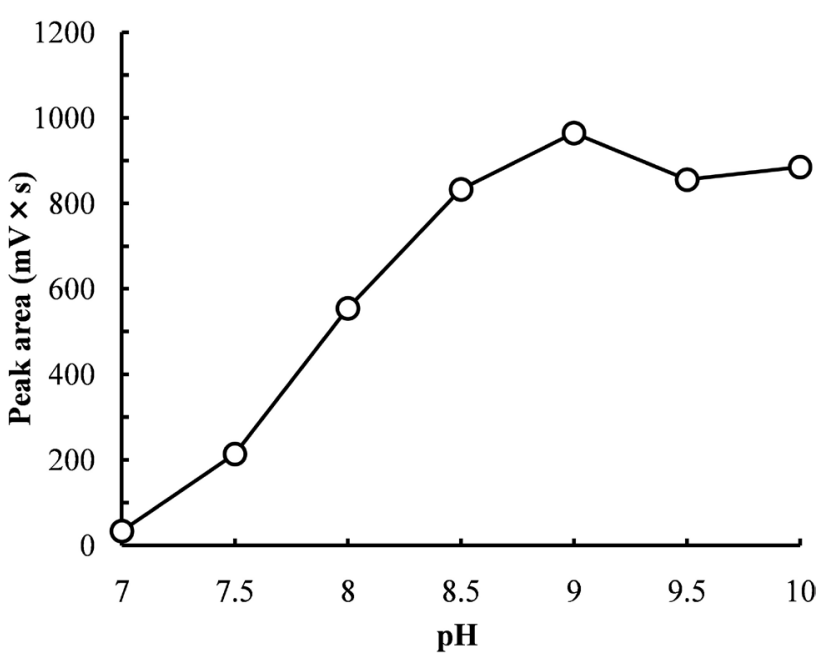

(b)

Figure 2. (a) Plot of peak area versus reaction time for formation of the RK derivative with DBD-COCl. Data are mean values of two experiments; (b) Plot of peak area versus various $\mathrm{pH}$ values for formation of the RK derivative with DBD-COCl. Data are mean values of two experiments. 
at $\mathrm{pH} 9.0$ showed the maximum. The peak area was remarkably low at neutral $\mathrm{pH}$, and was tended to decrease at $\mathrm{pH} 9.5$ and 10.0. Thus, the derivatization time of $3 \mathrm{~min}$ at $\mathrm{pH} 9.0$ was chosen for the assay.

\subsection{Chromatogram}

Figure 3 shows typical chromatograms obtained from (A) standard sample (1 $\mu \mathrm{g} / \mathrm{mL}$ ) and (B) test sample of a fragrance mist (diluted 1600-fold with distilled water). The retention time of DBD-CO-RK derivative was $16.6 \mathrm{~min}$. A peak of DBD-CO-RK derivative was observed in the test sample. The running time was set at $30 \mathrm{~min}$, because unknown peak was detected at $28.8 \mathrm{~min}$.

\subsection{Standard Curves of RK}

The standard curve of RK was constructed by plotting integrated peak area vs. concentration. The calibration plot was linear (slope, 903.5; intercept, +36.58 ) in the range of 0.05 to $2.5 \mu \mathrm{g} / \mathrm{mL}$ with a correlation coefficient $\left(r^{2}\right)$ value of 0.9988 . The lower limit of detection for RK was estimated as described above. The values of the lower limit of detection and quantification were $0.01 \mu \mathrm{g} / \mathrm{mL}$ (absolute amount of $0.3 \mathrm{pmol}, 0.05 \mathrm{ng}$ ) and $0.03 \mu \mathrm{g} / \mathrm{mL}$ (absolute amount of $0.9 \mathrm{pmol}, 0.15$

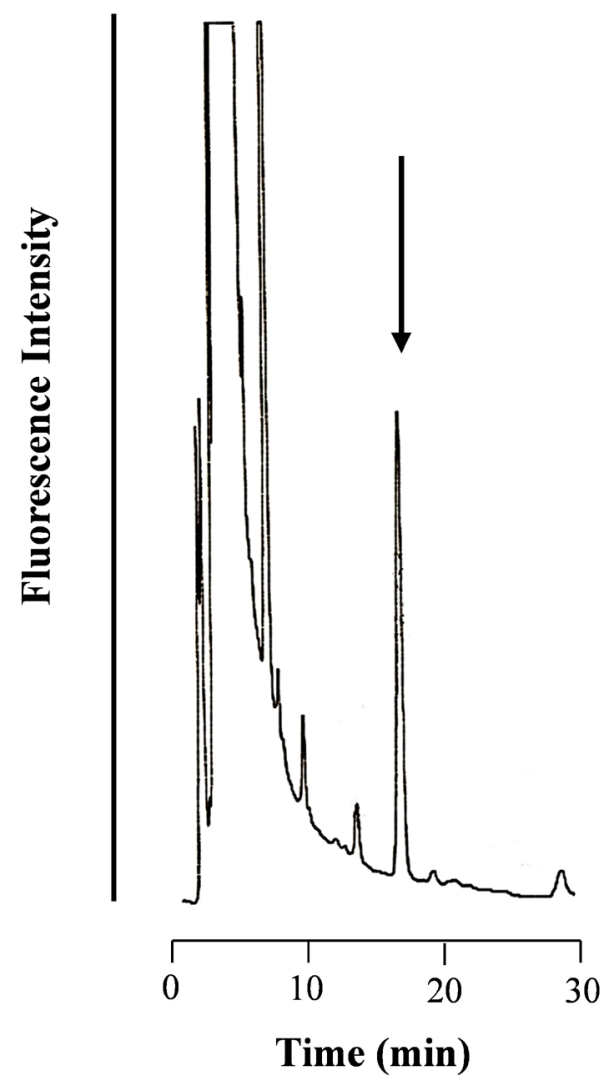

(a)

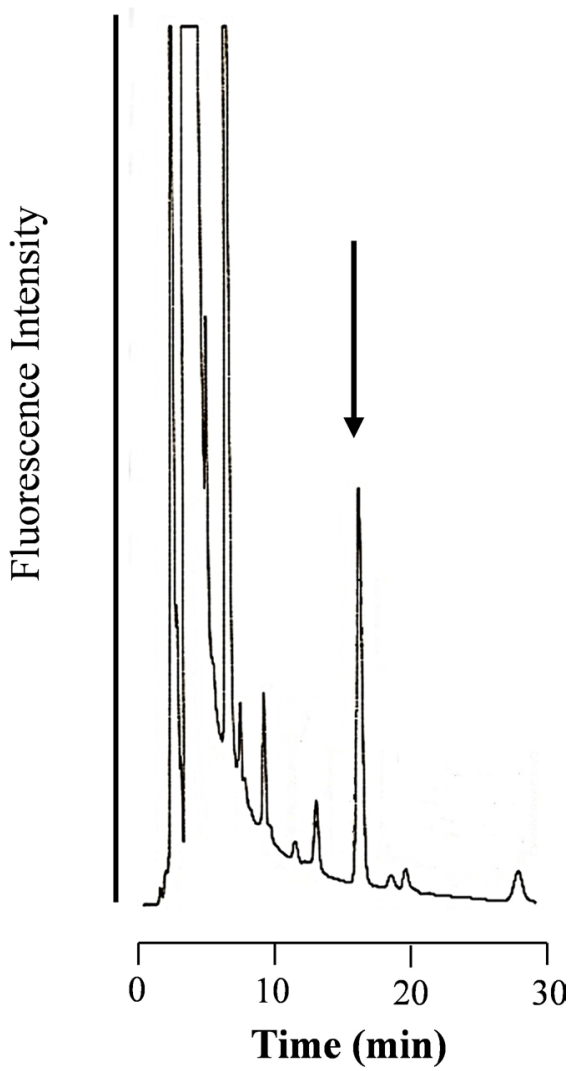

(b)

Figure 3. Typical chromatograms obtained for (a) standard sample $(1 \mu \mathrm{g} / \mathrm{mL})$ and (b) test sample of a fragrance mist (1600-fold diluted sample). Retention time of DBD-CO-RK derivative (arrowed peak): $16.6 \mathrm{~min}$. 
ng), respectively.

RK is a volatile compound, and has been analyzed by GC-mass spectrometry [10] and GC with a flame ionization detector [11], but those reports did not clearly describe the sensitivity of their methods. Also, the lower limit of detection of RK with the previous HPLC methods was not established [8] [9] [13]. However, HPLC analysis using a pre-column derivatization with NBD-H showed detection limits of $1.8 \mathrm{pmol}$ [14]. Therefore, the sensitivity of the present method ( 0.3 pmol RK) appears to be improved.

\subsection{Precision and Accuracy}

Precision and accuracy in intra-day and inter-day assays of RK are shown in $\mathrm{Ta}$ ble 1. In the intra-day assay, the range of standard deviation was within $4.3 \%$ to $8.6 \%$ of the mean and recovery was within the range of $96.8 \%$ to $102.2 \%$. In the inter-day assay, the range of standard deviation was within $5.7 \%$ to $10.0 \%$ of the mean and recovery was within the range of $97.6 \%$ to $100.8 \%$.

\subsection{Analysis of a Fragrance Mist}

The developed method was used to determine RK in fragrance mist and in fragrance mist spiked with authentic standard. The concentration of RK in fragrance mist was $1.20 \pm 0.08 \mathrm{mg} / \mathrm{mL}$ (average \pm S.D., range, 1.10 to $1.31 \mathrm{mg} / \mathrm{mL}$, $n=5$, data not shown). Recovery of RK from spiked fragrance mist was $91.8 \pm$ $5.4 \%$ (average \pm S.D., range, 84.2 to $98.2 \%, n=5$, data not shown). The present concentration of RK in fragrance mist was almost fully consisted with previous data $(1.18 \pm 0.07 \mathrm{mg} / \mathrm{mL})$ [14]. Those data suggest the present assay would be suitable for RK determination.

\section{Conclusion}

An improved HPLC-fluorescence method for determination of RK in fragrance mist has been developed by using $\mathrm{DBD}-\mathrm{COCl}$ as a fluorescence-labeling reagent. Since derivatization conditions are mild and rapid, the present method would be more useful than previous method [14]. Also, sensitivity of the method is 6-fold improved. The mean content of $\mathrm{RK}$ in the mist $(1.00 \mathrm{~mL})$ was found to be $1.20 \pm$

Table 1. Intra- and inter-day assay reproducibility for determination of RK.

\begin{tabular}{cccc}
\hline $\mathrm{RK}(\mu \mathrm{g} / \mathrm{mL})$ & Measured $(\mathrm{mg} / \mathrm{L}$, Mean \pm S.D., $\mathrm{n}=5)$ & C.V. $(\%)$ & Recovery $(\%)$ \\
\hline Intra-day assay & & & \\
0.05 & $0.0491 \pm 0.0042$ & 8.6 & 98.2 \\
0.5 & $0.511 \pm 0.022$ & 4.3 & 102.2 \\
2.5 & $2.42 \pm 0.11$ & 4.5 & 96.8 \\
Inter-day assay & & & \\
0.05 & $0.0488 \pm 0.0049$ & 10.0 & 97.6 \\
0.5 & $0.504 \pm 0.035$ & 6.9 & 100.8 \\
2.5 & $2.44 \pm 0.14$ & 5.7 & 97.6 \\
\hline
\end{tabular}


$0.08 \mathrm{mg}$. This system should be suitable for routine quality assessment of fragrance mist and should be readily adaptable for measurement of RK levels in other cosmetics.

\section{References}

[1] Morimoto, C., Satoh, Y, Hara, M., Inoue, S., Tsujita, T. and Okuda, H. (2005) Anti-Obese Action of Raspberry Ketone. Life Sciences, 77, 194-204. https://doi.org/10.1016/j.lfs.2004.12.029

[2] Wang, L., Meng, X. and Zhang, F. (2012) Raspberry Ketone Protects Rats Fed High-fat Diets against Nonalcoholic Steatohepatitis. Journal of Medicinal Food, 15, 495-503. https://doi.org/10.1089/jmf.2011.1717

[3] Park, K.S. (2015) Raspberry Ketone, a Naturally Occurring Phenolic Compound, Inhibits Adipogenic and Lipogenic Gene Expression in 3T3-L1 Adipocytes. Pharmaceutical Biology, 53, 870-875. https://doi.org/10.3109/13880209.2014.946059

[4] Fukuda, Y., Nagano, M., Arimatsu, Y. and Futatsuka, M. (1998) An Experimental Study on Depigmenting Activity of 4-( $p$-Hydroxyphenyl)-2-butanone in C57 Black Mice. Journal of Occupational Health, 40, 97-102. https://doi.org/10.1539/joh.40.97

[5] Victor Lin, C.H., Ding, H.Y., Kuo, S.Y., Chin, L.W., Wu, J.Y. and Chang, T.S. (2011) Evaluation of in Vitro and in Vivo Depigmenting Activity of Raspberry Ketone from Rheum officinale. International Journal of Molecular Sciences, 12, 4819-4835. https://doi.org/10.3390/ijms12084819

[6] Kim, M., Baek, H.S., Lee, M., Park, H., Shin, S.S., Choi, D.W. and Lim, K.M. (2016) Rhododenol and Raspberry Ketone Impair the Normal Proliferation of Melanocytes through Reactive Oxygen Species-Dependent Activation of GADD45. Toxicology in Vitro, 32, 339-346. https://doi.org/10.1016/j.tiv.2016.02.003

[7] Aoyama, Y., Ito, A., Suzuki, K., Suzuki, T., Tanemura, A., Nishigori, C., Ito, M., Katayama, I., Sugiura, S. and Matsunaga, K. (2014) The First Epidemiological Report of Rhododenol-Induced Leukoderma in Japan Based on a Nation-Wide Survey. The Japanese Journal of Dermatology, 124, 2095-2109.

[8] Fogy, I., Grundmann, H., Schmid, E.R., Huber, J.F.K. and Holzer, H. (1981) High-Pressure Liquid Chromatographic Determination of Raspberry Ketone in Natural and Artificially Aromatized Raspberry Products. Deutsche Lebensmit-tel-Rundschau, 77, 271-275.

[9] Borejsza-Wysocki, W., Goers, S.K., McArdle, R.N. and Hrazdina, G. (1992) ( $p$-Hydroxyphenyl)butan-2-One Levels in Raspberries Determined by Chromatographic and Organoleptic Methods. Journal of Agricultural and Food Chemistry, 40, 1176-1177. https://doi.org/10.1021/jf00019a018

[10] Perez, R.L. (1983) Gas Chromatographic Determination of Raspberry Ketone and Malathion in Insect Bait Concentrates. Journal of Chromatography A, 259, 176-180. https://doi.org/10.1016/S0021-9673(01)87993-0

[11] Grob, Jr.K. and Stoll, J.M. (1986) Loop-Type Interface for Concurrent Solvent Evaporation in Coupled HPLC-GC. Analysis of Raspberry Ketone in a Raspberry Sauce as an Example. Journal of High Resolution Chromatography, 9, 518-523. https://doi.org/10.1002/jhrc.1240090906

[12] Beekwilder, J., van der Meer, I.M., Sibbesen, O., Broekgaarden, M., Qvist, I., Joern D. Mikkelsen, J.D. and Hall, R.D. (2007) Microbial Production of Natural Raspberry Ketone. Biotechnology Journal, 2, 1270-1279. https://doi.org/10.1002/biot.200700076 
[13] Lili, W., Yansong, W., Yan, Z., Xianjun, M., Lei, Y. and Fengqing, Z. (2011) Deter-mination of Raspberry Ketone in Raspberry by High-Performance Liquid Chromatography Tandem Mass Spectrometry. 2011 International Conference on Human Health and Biomedical Engineering (HHBE), Jilin, 19-22 August 2011, 62-65. https://doi.org/10.1109/HHBE.2011.6027897

[14] Higashi, Y. (2016) Simple HPLC-fluorescence Determination of Raspberry Ketone in Fragrance Mist after Pre-Column Derivatization with 4-Hydrazino-7-nitro-2,1,3benzoxadiazole. Journal of Analytical Sciences, Methods and Instrumentation, 6, 44-49. https://doi.org/10.4236/jasmi.2016.62006

[15] Higashi, Y. (2015) Simple Determination of $17 \alpha$-Ethynylestradiol in Hair Restorer by High-Performance Liquid Chromatography Coupled with Fluorescence Detection after Pre-Column Derivatization 4-( $N$-Chloroformylmethyl- $N$-methylamino) -7-nitro-2,1,3-benzoxadiazole. Austin Chromatography, 2, 1-4.

[16] Higashi, Y. (2015) Simple HPLC-Fluorescence Determination of Eugenol in Clove Oil after Pre-Column Derivatization with 4-( $N$-chloroformylmethyl- $N$-methylamino)-7nitro-2,1,3-benzoxadiazole. Journal of Analytical Chemistry, 70, 1401-1405. https://doi.org/10.1134/S1061934815110179

[17] Higashi, Y. (2015) Development of Simultaneous HPLC-Fluorescence Assay of Phenol and Chlorophenols in Tap Water after Pre-Column Derivatization with 3-Chlorocarbonyl-6,7-dimethoxy-1-methyl-2 $(1 H)$-quinoxalinone. Detection, 4 , 16-24. https://doi.org/10.4236/detection.2016.41003 